\title{
Imatinib-induced apoptosis of gastric cancer cells is mediated by endoplasmic reticulum stress
}

\author{
JUNG LIM KIM ${ }^{1 *}$, DAE-HEE LEE ${ }^{1,2^{*}}$, SOYEON JEONG ${ }^{1}$, BO RAM KIM ${ }^{1}$, YOO JIN NA ${ }^{2}$, \\ SEONG HYE PARK ${ }^{2}$, MIN JEE JO ${ }^{2}$, YOON A. JEONG ${ }^{2}$ and SANG CHEUL OH ${ }^{1,2}$ \\ ${ }^{1}$ Division of Oncology, Department of Internal Medicine, Korea University College of Medicine, \\ Korea University Guro Hospital, Seoul 08308; ${ }^{2}$ Graduate School of Medicine, \\ Korea University College of Medicine, Seoul 02841, Republic of Korea
}

Received June 7, 2018; Accepted November 30, 2018

DOI: $10.3892 /$ or.2018.6945

\begin{abstract}
Imatinib is a powerful tyrosine kinase inhibitor that specifically targets BCR-ABL, c-KIT, and PDGFR kinases, and is used in the treatment of chronic myelogenous leukemia, gastrointestinal stromal tumors, and other types of cancers. However, the possible anticancer effects of imatinib in gastric cancer have not yet been explored. The present study evaluated the in vitro effects of imatinib on gastric cancer cells and determined the molecular mechanism underlying these effects. We determined that imatinib induced mitochondria-mediated apoptosis of gastric cancer cells by involving endoplasmic reticulum (ER) stress-associated activation of c-Jun $\mathrm{NH}_{2}$-terminal kinase (JNK). We also found that imatinib suppressed cell proliferation in a time- and dose-dependent manner. Cell cycle analysis revealed that imatinib-treated AGS cells were arrested in the G2/M phase of the cell cycle. Moreover, imatinib-treated cells exhibited increased levels of phosphorylated JNK, and of the transcription factor C/EBP homologous protein, an ER stress-associated apoptotic molecule. Results of cell viability assays revealed that treatment with a combination of imatinib and chemotherapy agents irinotecan or 5-Fu synergistically
\end{abstract}

Correspondence to: Dr Sang Cheul Oh, Graduate School of Medicine, Korea University College of Medicine, 73 Inchon-ro, Seonbuk-gu, Seoul 02841, Republic of Korea

E-mail: sachoh@korea.ac.kr

*Contributed equally

Abbreviations: BAX, BCL2-associated X protein; CHOP, C/EBPhomologous protein; eIF $2 \alpha$, eukaryotic translation initiation factor $2 \alpha$; $\mathrm{ER}$, endoplasmic reticulum; FITC, fluorescein isothiocyanate; JNK, c-Jun NH2-terminal kinase; MAPK, mitogen-activated protein kinase; MTT, 3-(4,5-dimethylthiazol-2-ly)-2,5-diphenyl tetrazolium bromide; PARP, poly(ADP-ribose) polymerase; PBS, phosphate-buffered saline; PI, propidium iodide; ROS, reactive oxygen species

Key words: imatinib, gastric cancer, endoplasmic reticulum stress, c-Jun $\mathrm{NH}_{2}$-terminal kinase inhibited cell growth, compared with treatment with any of these drugs alone. These data indicated that imatinib exerted cytotoxic effects on gastric cancer cells by inducing apoptosis mediated by reactive oxygen species generation and ER stress-associated JNK activation. Furthermore, we revealed that imatinib induced the apoptosis of gastric cancer cells by inhibiting platelet-derived growth factor receptor signaling. Collectively, our results strongly support the use of imatinib in the treatment of treating gastric cancer.

\section{Introduction}

Gastric cancer is a leading cause of cancer-related deaths worldwide (1). Recent studies have revealed that immune-targeting therapy improves the survival of patients with gastric cancer. Numerous chemotherapy regimens have been clinically examined for treating gastric cancer; however, there is an urgent need for novel therapeutic agents for the treatment of gastric cancer.

Imatinib mesylate (imatinib) is a powerful tyrosine kinase inhibitor that specifically targets BCR-ABL, KIT, and platelet-derived growth factor receptor (PDGFR) kinases and is used for treating chronic myelogenous leukemia (CML), gastrointestinal stromal tumors (GISTs), and other types of cancers $(2,3)$. However, the cellular and molecular mechanisms underlying the antitumor effects of imatinib are unknown.

PDGFR $\alpha$ and PDGFR- $\beta$ are transmembrane tyrosine kinase receptors whose ligands play critical roles in cancer cell migration and proliferation (4-6). The PI3K/AKT pathway is an important downstream signaling pathway of PDGFR that plays important roles in promoting cell proliferation, suppressing cell motility, and inhibiting cell apoptosis. Increased PDGFR expression is also detected in various solid cancers (7).

The endoplasmic reticulum (ER) plays a major role in protein synthesis and maturation, lipid synthesis, calcium homeostasis, and protein folding (8). Misfolded and unfolded proteins, particularly secretory and transmembrane proteins produced in the ER, induce an evolutionarily conserved unfolded protein response (UPR), an ER stress pathway, which in turn induces various pathological events such as inflammation, aging, and neurodegenerative disorders. The UPR, which 
improves folding, is a survival response triggered by cells to restore ER homeostasis. Chronic accumulation of unfolded proteins in the ER may lead to death receptor-independent and mitochondria-mediated apoptotic pathways (9-12).

At low concentrations, intracellular oxidants function as signal transducers to induce growth factors, hypoxia, and other receptor-ligand systems $(13,14)$. However, at concentrations above threshold levels, these oxidants induce damage of lipids, proteins, RNA, and DNA, thus triggering cell death through apoptosis and/or necrosis (15-17). Reactive oxygen species (ROS) such as oxygen ions and peroxides are chemically reactive molecules containing oxygen that are formed as natural by-products of normal oxygen metabolism and play important roles in cell signaling and homeostasis (18). Biological functions of ROS and their potential roles in cancer development and disease progression have been investigated over the past several decades. ROS mediate cancer cell apoptosis induced by various anticancer agents and other stimuli (19). However, various studies have also shown that anticancer agents increase apoptosis of malignant cells by decreasing ROS production (20).

However, the role of ROS, and mechanisms underlying their antitumorigenic function in solid tumors, particularly gastric cancer, are unknown. In the present study, we evaluated whether imatinib exerted antitumorigenic effects on gastric cancer cells by inducing apoptosis. Our results indicated that IRE1 $\alpha$-c-Jun $\mathrm{NH}_{2}$-terminal kinase (JNK)- and C/EBP homologous protein (CHOP)-associated ER stress was involved in imatinib-induced apoptosis of gastric cancer cells, suggesting that imatinib is a potential chemotherapeutic agent for treating gastric cancer.

\section{Materials and methods}

Reagents and antibodies. Imatinib was purchased from Novartis International AG (Basel, Switzerland). JNK inhibitor SP600125 was obtained from EMD/Merck KGaA (Darmstadt, Germany). Rabbit antibodies against PARP (1:1,000 dilution; cat. no. 9542), caspase-3 (1:1,000 dilution; cat. no. 9662), Bid (1:1,000 dilution; cat. no. 2002), Bim (1:1,000 dilution; cat. no. 2819), Puma (1:1,000 dilution; cat. no. 4976), Noxa (1:1,000 dilution; cat. no. 14766), p-JNK (1:1,000 dilution; cat. no. 9251), JNK (1:1,000 dilution; cat. no. 9252), PDGFR- $\alpha$ (1:1,000 dilution; cat. no. 3164), PDGFR- $\beta$ (1:1,000 dilution; cat. no. 3169), p-PDGFR- $\alpha$ (1:1,000 dilution; cat. no. 4547), p- PDGFR- $\beta$ (1:1,000 dilution; cat. no. 3161), AKT (1:1,000 dilution; cat. no. 9272), p-AKT (1:1,000 dilution; cat. no. 4060), 4EBP1 (1:1,000 dilution; cat. no. 9644), p-4EBP1 (1:1,000 dilution; cat. no. 2855), p70 S6 kinase (1:1,000 dilution; cat. no. 2708), p-p70 S6 kinase (Ser371) (1:1,000 dilution; cat. no. 9208), p-p70 S6 kinase (Thr 389) (1:1,000 dilution; cat. no. 9205), mTOR (1:1,000 dilution; cat. no. 2983), p38 MAPK (1:1,000 dilution; cat. no. 9212), p-p38 MAPK (1:1,000 dilution; cat. no. 9211), p44/42 MAPK (ERK1/2) (137F5) (1:1,000 dilution; cat. no. 4695), p-p44/42 MAPK (Erk1/2) (Thr202/Tyr204) (1:1,000 dilution; cat. no. 4370), eIF2 $\alpha$ (D7D3) (1:1,000 dilution; cat. no. 5324), p-eIF2 $\alpha$ (Ser51) (1:1,000 dilution; cat. no. 3597) and GRP94 (1:1,000 dilution; cat. no. 2104) and IRE1 $\alpha$ (1:1,000 dilution; cat. no. 3294) were obtained from Cell Signaling Technology, Inc. (Beverly, MA, USA). Rabbit antibody against p-IRE1 $\alpha$
(1:1,000 dilution; cat. no. ab48187) were obtained from Abcam (Cambridge, UK). Mouse antibodies against BCL2-associated X protein (Bax) ATF6 (1:1,000 dilution; cat. no. sc-20067), Bcl-2 (1:1,000 dilution; cat. no. sc-509), Survivin (1:1,000 dilution; cat. no. sc-17779) and CHOP (GADD 153) (1:1,000 dilution; cat. no. sc-7351) were purchased from Santa Cruz Biotechnology, Inc. (Dallas, TX, USA). Mouse antibodies against ATF6 (1:1,000 dilution; cat. no. NBP1-40256) were obtained from Novus Biologicals, LLC (Littleton, CO, USA). Anti-actin (1:2,000 dilution; cat. no. A2228) and DCFH-DA (cat. no. D6883) were purchased from Sigma-Aldrich; Merck KGaA (Darmstadt, Germany).

Cell culture. Human gastric cancer cell line AGS was obtained from the American Type Culture Collection (ATCC; Manassas, VA, USA), and SNU-638 and MKN45 cell lines were purchased from the Korean Cell Line Bank (Seoul, Korea). $\mathrm{CHOP}^{-/-}$and corresponding wild-type MEF cell lines were provided by Dr Randal J. Kaufman (Sanford Burnham Medical Research Institute, CA, USA). Gastric cancer cells were cultured in RPMI-1640 medium (Gibco; Thermo Fisher Scientific, Inc., Waltham, MA, USA) supplemented with $10 \%$ fetal bovine serum (FBS) and 1\% antibiotic-antimycotic solution (Gibco; Thermo Fisher Scientific, Inc.) at $37^{\circ} \mathrm{C}$ in a humidified atmosphere of $5 \% \mathrm{CO}_{2}$.

Cell viability assay. Cell growth rate and viability were determined by performing 3-(4,5-dimethylthiazol-2-ly)-2,5diphenyl tetrazolium bromide (MTT)-based colorimetric assays (Sigma-Aldrich; Merck KGaA). Cells were grown in 96-well plates containing medium supplemented with $10 \%$ fetal bovine serum at a density of $1 \times 10^{4}$ cells/well. The medium in each well contained different concentrations of imatinib. After $48 \mathrm{~h}, 50 \mu \mathrm{l}$ MTT solution was added to each well, and the cells were incubated at $37^{\circ} \mathrm{C}$ for $4 \mathrm{~h}$. Next, the supernatant was aspirated, and the dye was solubilized using $200 \mu$ l dimethyl sulfoxide (DMSO). Cell viability was determined according to the manufacturer's instructions by measuring the absorbance in individual wells at $595 \mathrm{~nm}$ using a microplate reader.

Cell cycle and apoptosis analyses. Cell cycle was analyzed by performing propidium iodide (PI) staining. Adherent cells were harvested by treatment with trypsin and were fixed with $5 \mathrm{mM}$ EDTA and $85 \%$ ethanol. Fixed cells were incubated with $50 \mu \mathrm{g} / \mathrm{ml} \mathrm{PI}$ and $20 \mu \mathrm{g} / \mathrm{ml} \mathrm{RNase}$ at $37^{\circ} \mathrm{C}$ for $30 \mathrm{~min}$ and were analyzed by performing flow cytometry. Apoptotic cells were stained using an Annexin V-fluorescein isothiocyanate (FITC) kit (Beckman Coulter, Inc., Brea, CA, USA), according to the manufacturer's instructions, and were then analyzed.

Western blot analysis. Cells harvested $48 \mathrm{~h}$ after imatinib treatment were centrifuged at $14,000 \mathrm{xg}$ and $4^{\circ} \mathrm{C}$ for $5 \mathrm{~min}$ and were washed twice with phosphate-buffered saline (PBS). Next, the cells were lysed in $30 \mu 1$ ice-cold RIPA buffer and were centrifuged again at $14,000 \mathrm{x} \mathrm{g}$ and $4^{\circ} \mathrm{C}$ for $30 \mathrm{~min}$. The obtained pellet was stored at $-70^{\circ} \mathrm{C}$ for further analysis. Protein concentrations were determined using the Bradford method (Bio-Rad Laboratories, Inc., Hercules, CA, USA). Lysates corresponding to equal protein amounts were boiled in sample buffer for $5 \mathrm{~min}$. Next, the samples were resolved by sodium dodecyl 

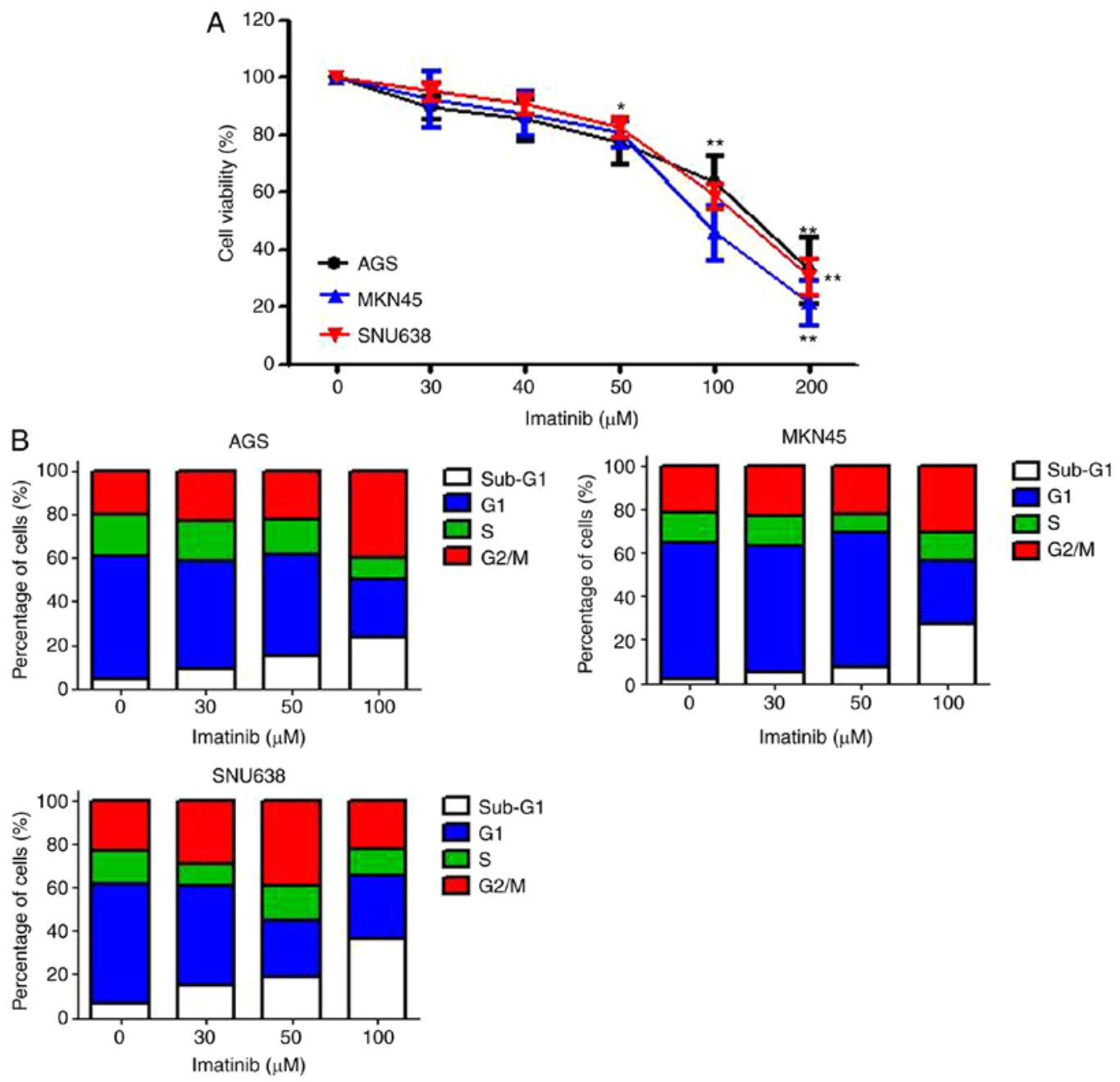

Figure 1. Imatinib decreases the viability of gastric cancer cells. (A) AGS, MKN45, and SNU638 cells were treated with various concentrations of imatinib for $48 \mathrm{~h}$, and cell viability was assessed by performing MTT assays. Data are expressed as the means \pm SD of three independent experiments. (B) AGS, MKN45, and SNU638 cells were stained with PI after incubation with the indicated concentration of imatinib for $48 \mathrm{~h}$, and the number of cells in the sub-G1, G1, $\mathrm{S}$, and G2-M phases was analyzed by performing flow cytometry. Each bar corresponds to the mean percentage of cells in each cell cycle phase from three independent experiments. ${ }^{*} \mathrm{P}<0.05$ and ${ }^{* *} \mathrm{P}<0.01$ compared with the control cells.

sulfate-polyacrylamide gel electrophoresis (SDS-PAGE) on 10 or $12 \%$ gels, with $50 \mu \mathrm{g}$ total protein loaded in each lane of the gel. The resolved proteins were transferred onto a $0.45-\mu \mathrm{m}$ nitrocellulose membranes. The membranes were blocked with 5\% non-fat dry milk in Tris-buffered saline with Tween-20 (TBST) buffer for $2 \mathrm{~h}$ to prevent non-specific binding, and was then washed three times with TBST for 10 min each. Next, the membrane was incubated with specific primary antibodies, followed by incubation at $4^{\circ} \mathrm{C}$ overnight with horseradish peroxidase-conjugated secondary antibody and then incubated with anti-mouse (1:2,500 dilution; cat. no. 170-6516; Bio-Rad Laboratories) or anti-rabbit (1:2,500 dilution; cat. no. 7074; Cell Signaling Technology, Inc.) specific polyclonal secondary antibodies for $2 \mathrm{~h}$ at $4^{\circ} \mathrm{C}$. Then, the membrane was washed three times with TBST for $10 \mathrm{~min}$ each. Signals were detected by exposure to X-ray film using an EZ-Western Lumi Pico kit (DoGEN, Seoul, Korea; cat. no. DG-WP-250).

ROS generation. ROS generation was assessed in cells treated with imatinib for 30 or $60 \mathrm{~min}$. Intracellular ROS levels were determined using $2^{\prime}, 7^{\prime}$-dichlorodihydrofluorescein diacetate (DCFH-DA), which oxidizes within cells to fluorescent dichlorofluorescein. Control and imatinib-treated cells were incubated with $100 \mu \mathrm{M}$ DCFH-DA for $30 \mathrm{~min}$ at $37^{\circ} \mathrm{C}$.

Next, the cells were fixed in $3.7 \%$ paraformaldehyde for $10 \mathrm{~min}$ at room temperature. Subsequently, the cells were co-stained with $2 \mu \mathrm{M}$ 4',6-diamidino-2-phenylindole (Molecular Probes; Thermo Fisher Scientific, Inc.) at $37^{\circ} \mathrm{C}$. After washing three times with PBS, the cells were mounted using VECTASHIELD mounting medium (Vector Laboratories, Inc., Burlingame, CA, USA), and immunofluorescence was detected using a confocal microscope (Carl Zeiss $\mathrm{AG}$, Oberkochen, Germany). Then, $\mathrm{MEF}$ of $\mathrm{MEF} \mathrm{CHOP}^{-/}$cells were stained with $100 \mu \mathrm{M}$ DCFH-DA for $30 \mathrm{~min}$ at $37^{\circ} \mathrm{C}$. The cells were then transferred to FACS tubes and analyzed using the FL1 channel on a FACScan cytometer (BD Biosciences, Franklin Lakes, NJ, USA).

Statistical analysis. Statistical analysis was performed using GraphPad InStat 5 software (GraphPad Software, Inc., San Diego, CA, USA). Statistical significance was determined by one-way analysis of variance (ANOVA) followed by 


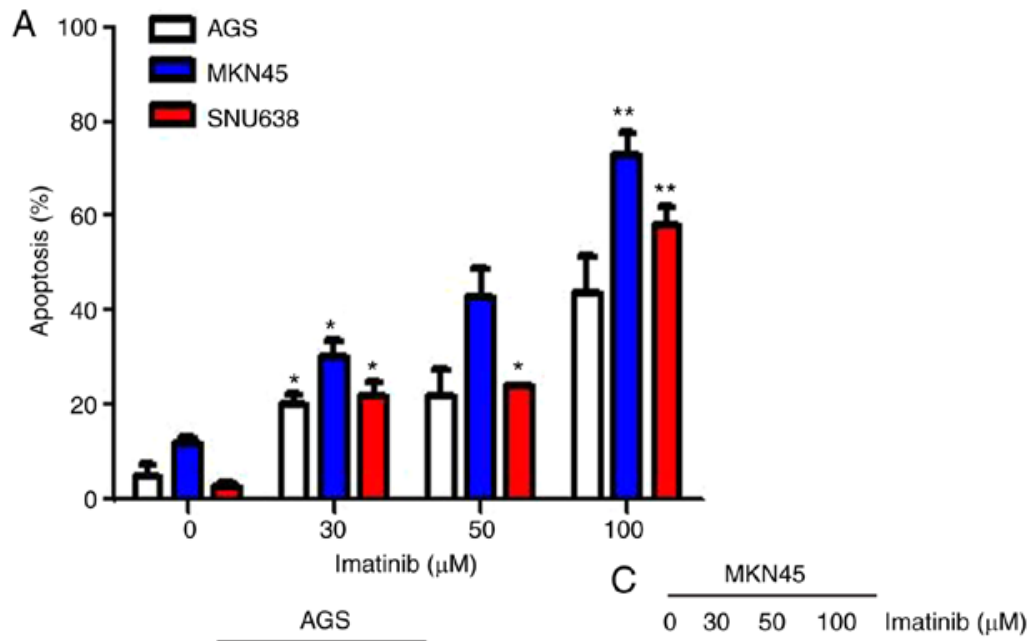

B

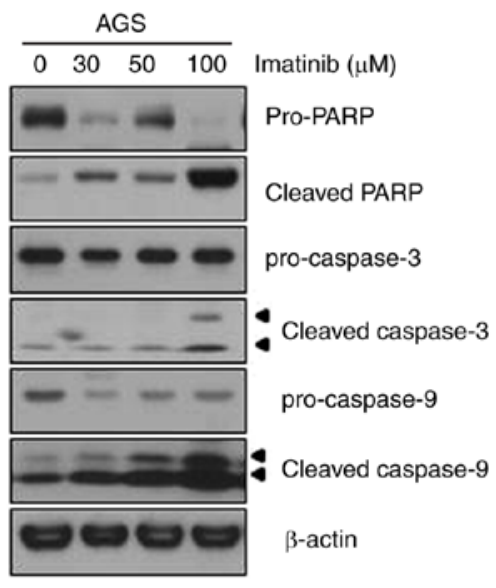

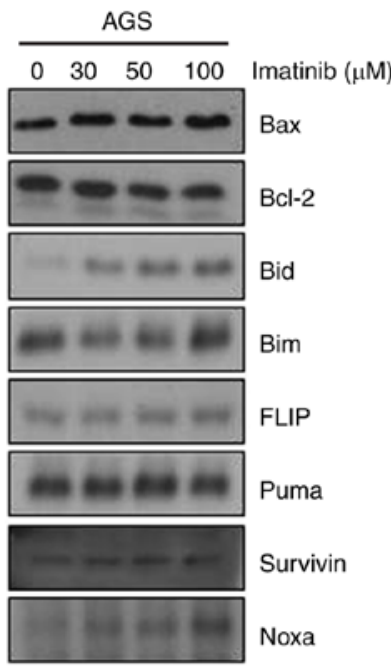

$\begin{array}{lllll}0 & 30 & 50 & 100 & \text { Imatinib }(\mu \mathrm{M})\end{array}$

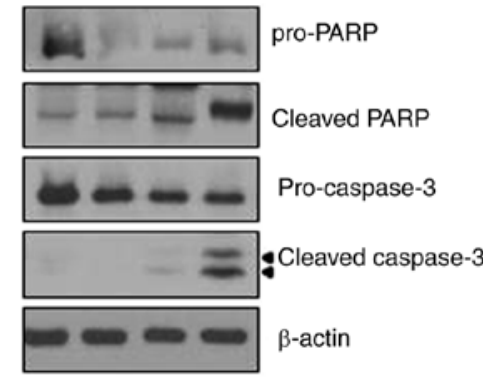

D

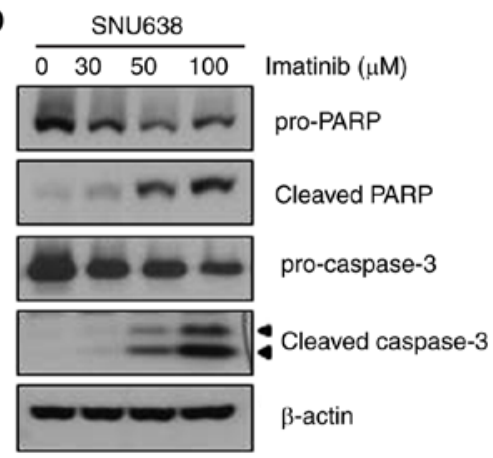

Figure 2. Imatinib induces the apoptosis of gastric cancer cells. (A) AGS, MKN45, and SNU638 cells were stained with Annexin V-FITC and PI after incubation with the indicated concentrations of imatinib for $48 \mathrm{~h}$, and the number of apoptotic cells was analyzed by performing flow cytometry. Statistical analysis of the results of flow cytometry. Annexin V/PI-positive cells were defined as apoptotic cells. Results are expressed as the means \pm standard error of three individual experiments. ${ }^{*} \mathrm{P}<0.05$ and ${ }^{* *} \mathrm{P}<0.01$ compared with the control cells. (B-D) AGS, MKN45, and SNU638 cells were treated with the indicated concentrations of imatinib for $48 \mathrm{~h}$. Levels of cleaved caspase-3, cleaved caspase-9, cleaved PARP, Bax, and Bcl-2 were determined by performing immunoblotting. $\beta$-actin was used as an internal standard. FITC, fluorescein isothiocyanate; PI, propidium iodide; Bax, BCL2-associated X protein; PARP, poly(ADP-ribose) polymerase.

Bonferroni post hoc test for multiple comparisons or Student's t-test. For all tests, $\mathrm{P}<0.05$ or $\mathrm{P}<0.01$ were considered to indicate statistically significant differences.

\section{Results}

Imatinib decreases the viability of gastric cancer cells. To investigate the antitumor activity of imatinib against gastric cancer cells (AGS, MKN45 and SNU638 cells), the cells were incubated at different concentrations of imatinib for $48 \mathrm{~h}$ and their viability was determined by performing MTT assays. Results of the MTT assays revealed that imatinib treatment significantly decreased cell viability in a dose-dependent manner. Statistically significant cytotoxic effects were observed after treatment with $>50 \mu \mathrm{M}$ imatinib (Fig. 1A). Next, we determined the effect of imatinib on cell cycle progression.
For this, the cells were treated with various concentrations of imatinib, and cell cycle progression was assessed after $48 \mathrm{~h}$ by performing flow cytometry with PI staining. Imatinib treatment for $48 \mathrm{~h}$ significantly increased the percentage of cells in the sub-G1 and G2/M phases of the cell cycle, in a dose-dependent manner. These data indicated that imatinib treatment arrested gastric cancer cells in the sub-G1 phase of the cell cycle (Fig. 1B), and also indicated that imatinib exerted anti-proliferative effects on gastric cancer cells.

Imatinib induces apoptosis of gastric cancer cells. We performed Annexin V/PI double staining to evaluate whether imatinib induced apoptosis of the three gastric cancer cell lines. Results of Annexin V/PI double staining revealed that the percentage of Annexin V/PI-positive cells significantly increased, indicating that imatinib treatment increased the 
A
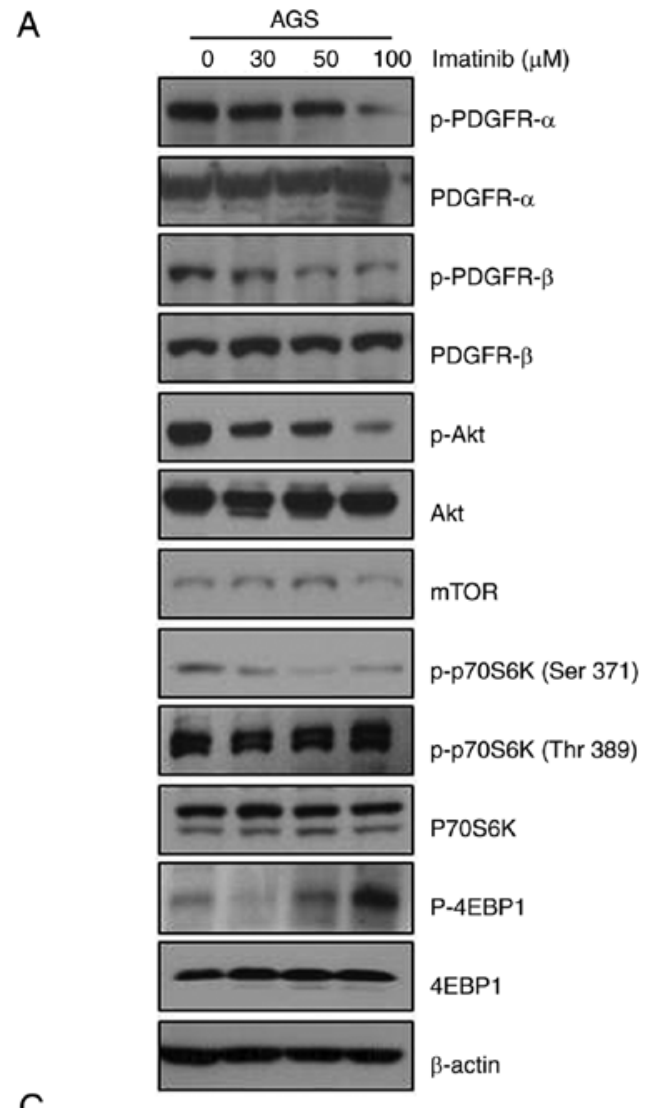

B

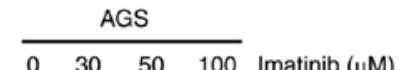

C

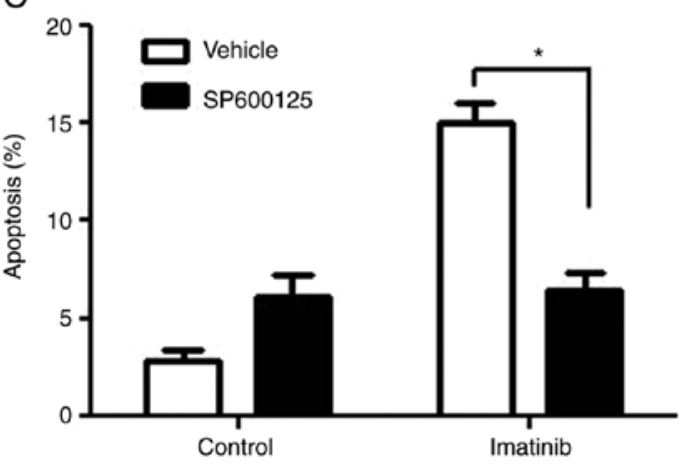

D

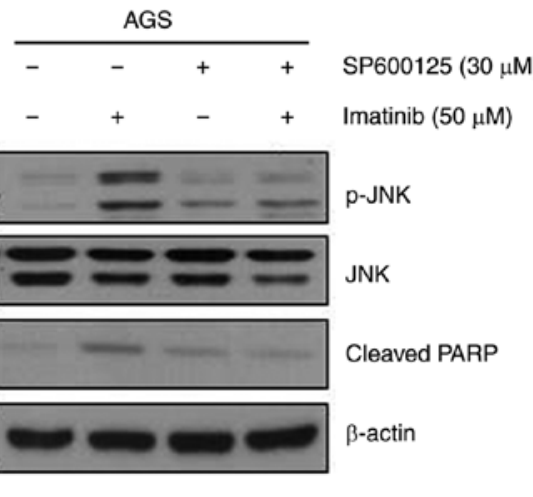

Figure 3. Imatinib induces apoptosis by phosphorylating JNK in gastric cancer cells. (A) AGS cells were treated with the indicated concentrations of imatinib for $48 \mathrm{~h}$. Expression levels of proteins associated with the PDGFR pathway were assessed by performing immunoblotting with the corresponding antibodies. $\beta$-actin was used as an internal standard. (B) AGS cells were treated with the indicated concentrations of imatinib for $48 \mathrm{~h}$, and the levels of JNK, p-JNK, p38, p-p38, ERK, p-ERK and $\beta$-actin were assessed by performing immunoblotting with the corresponding antibodies. (C) Blocking of the JNK pathway effectively suppressed imatinib-induced apoptosis of AGS cells. ${ }^{*} \mathrm{P}<0.05$ compared to the vehicle. (D) AGS cells were pretreated with $20 \mu \mathrm{M}$ JNK inhibitor (SP600125) for $1 \mathrm{~h}$, followed by treatment with $50 \mu \mathrm{M}$ imatinib for $48 \mathrm{~h}$. Levels of cleaved PARP, JNK and p-JNK were determined by performing immunoblotting. $\beta$-actin was used as an internal standard. JNK, c-Jun NH2-terminal kinase; PDGFR, platelet-derived growth factor receptor.

early apoptosis of gastric cancer cells (Fig. 2A). Next, we performed western blot analysis to confirm imatinib-induced apoptosis of gastric cancer cells, and to identify the underlying mechanism. Imatinib treatment for $48 \mathrm{~h}$ increased poly(ADP-ribose) polymerase (PARP) cleavage, and cleaved caspase-3 and -9 expression in AGS cells (Fig. 2B). Bcl-2 is an anti-apoptotic protein, and $\mathrm{Bax}$ is a pro-apoptotic protein. We observed that Bax and Bcl-2 levels were unaffected in imatinib-treated AGS cells. Pro-apoptotic Bcl-2 family proteins (Noxa and Bid) were induced in imatinib-treated cells. Similar results were obtained for imatinib-treated MKN45 and SNU638 gastric cancer cells (Fig. 2C and D). These results indicated that imatinib treatment induced apoptosis of gastric cancer cells.
Imatinib decreases PDGFR signaling in gastric cancer cells. Imatinib is a powerful tyrosine kinase inhibitor that specifically targets BCR-ABL, KIT, and PDGFR kinases, and is used for treating CML, GISTs, and other types of cancers (3,21-24). In the present study, c-KIT and BCR-ABL expression was not detected in the three gastric cancer cell lines (data not shown). Next, we examined the effects of imatinib on PDGFR signaling in AGS cells and found that imatinib efficiently suppressed PDGFR-induced downstream signaling (Fig. 3A). Imatinib inhibited the phosphorylation of PDGFR- $\alpha$, PDGFR- $\beta$, AKT and p70S6K (Ser371). Notably, the phosphorylation of PDGFR- $\beta$ decreased more markedly than that of PDGFR- $\alpha$ in imatinib-treated cells. However, no significant changes were observed in total protein levels in imatinib-treated cells. 
A

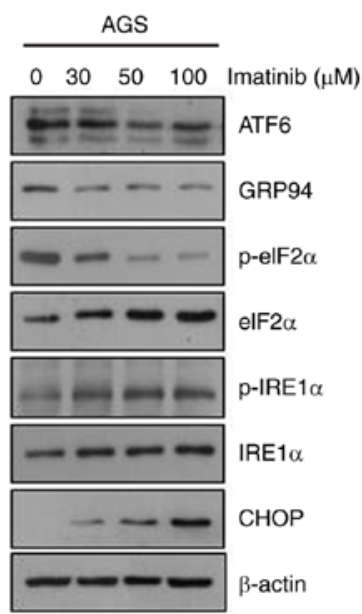

D

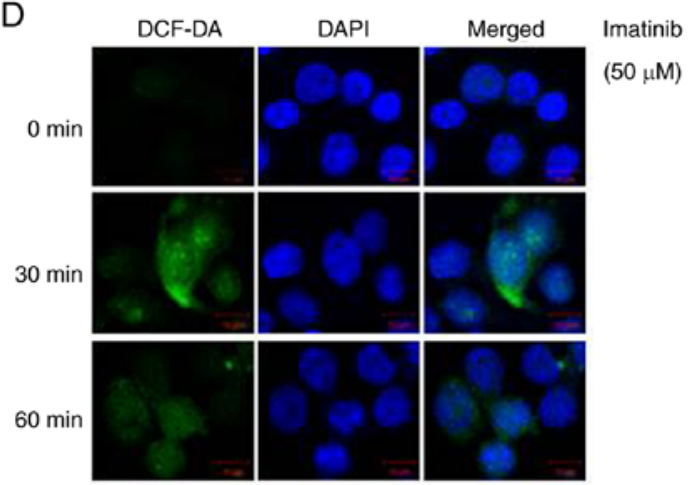

$\mathrm{F}$

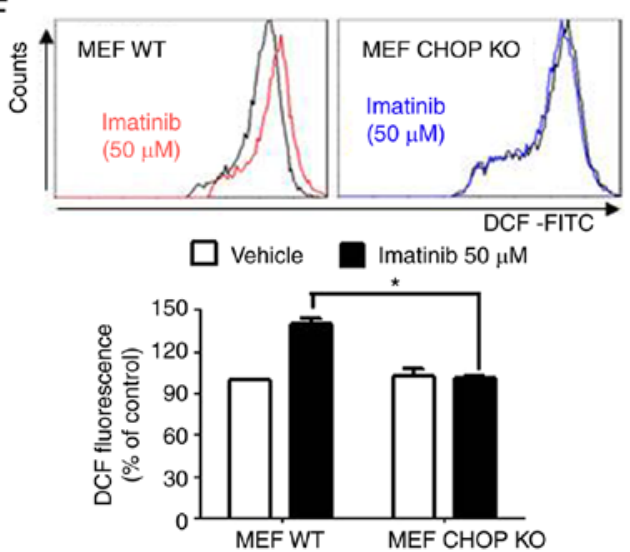

B

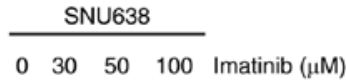

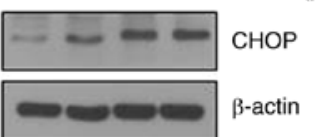

C
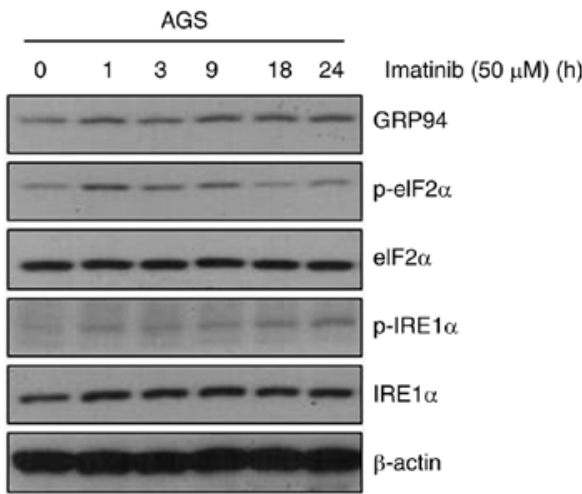

E

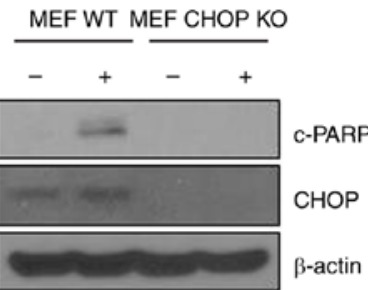

G

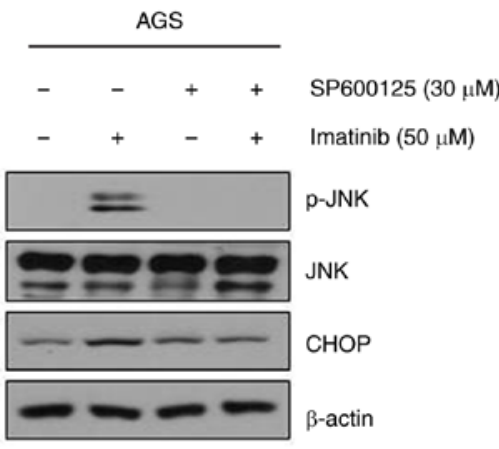

Figure 4. Imatinib-induced apoptosis is mediated by the ER stress pathway. (A-C) AGS and SNU638 cells were treated with the indicated concentrations of imatinib for $48 \mathrm{~h}$ (A and B) or with $50 \mu \mathrm{M}$ imatinib for the indicated time periods (C). Levels of ER stress pathway-associated proteins were assessed by performing immunoblotting with the corresponding antibodies (D). AGS cells were treated with $50 \mu \mathrm{M}$ imatinib for 30 or 60 min, stained with the FITC probe DCFH-DA $(10 \mu \mathrm{M})$ for $30 \mathrm{~min}$ at $37^{\circ} \mathrm{C}$, and were visualized under a confocal microscope. (E) Wild-type and $\mathrm{CHOP}^{-\digamma} \mathrm{MEFs}$ were treated with $50 \mu \mathrm{M}$ imatinib for $24 \mathrm{~h}$, and levels of cleaved PARP and CHOP were determined by performing immunoblotting. $\beta$-actin was used as an internal standard. (F) ROS generation of wild-type and $\mathrm{CHOP}^{-/}$MEFs was detected using DCFDA staining $1 \mathrm{~h}$ after the indicated treatments. Graphs represent the means \pm SEM. ${ }^{*}<0.05$ compared with treatment of imatinib in MEF WT cells. (G) AGS cells were pretreated with $20 \mu \mathrm{M} \mathrm{JNK}$ inhibitor (SP600125) for $1 \mathrm{~h}$, followed by treatment with $50 \mu \mathrm{M}$ imatinib for $48 \mathrm{~h}$. Levels of cleaved CHOP, JNK, and p-JNK were determined by immunoblotting. $\beta$-actin was used as an internal standard. ER, endoplasmic reticulum; fluorescein isothiocyanate; PARP, poly(ADP-ribose) polymerase; CHOP, C/EBP-homologous protein; ROS, reactive oxygen species; JNK, c-Jun NH2-terminal kinase.

Imatinib induces apoptosis by phosphorylating JNK in gastric cancer cells. Various cellular stresses and stimuli induce mitogen-activated protein kinase (MAPK) signaling that contributes to apoptotic induction (25). To determine the effect of imatinib on the expression and activity of molecules involved in MAPK signaling, we treated AGS cells with 30, 50 and $100 \mu \mathrm{M}$ imatinib for $48 \mathrm{~h}$ and performed western blot analysis. Imatinib treatment increased JNK phosphorylation in a dose-dependent manner, without affecting total JNK levels, but did not affect p38 and ERK phosphorylation (Fig. 3B). To verify the involvement of JNK in imatinib-induced apoptosis, the cells were co-treated with a JNK pathway inhibitor (SP600125) and imatinib $(50 \mu \mathrm{M})$. Treatment of gastric cancer cells with SP600125 significantly decreased their imatinib-induced apoptosis due to JNK inhibition (Fig. 3C). Moreover, treatment with SP600125 completely abolished imatinib-induced PARP activation (Fig. 3D). These results indicated that imatinib-induced apoptosis was mediated by the JNK-MAPK pathway. 

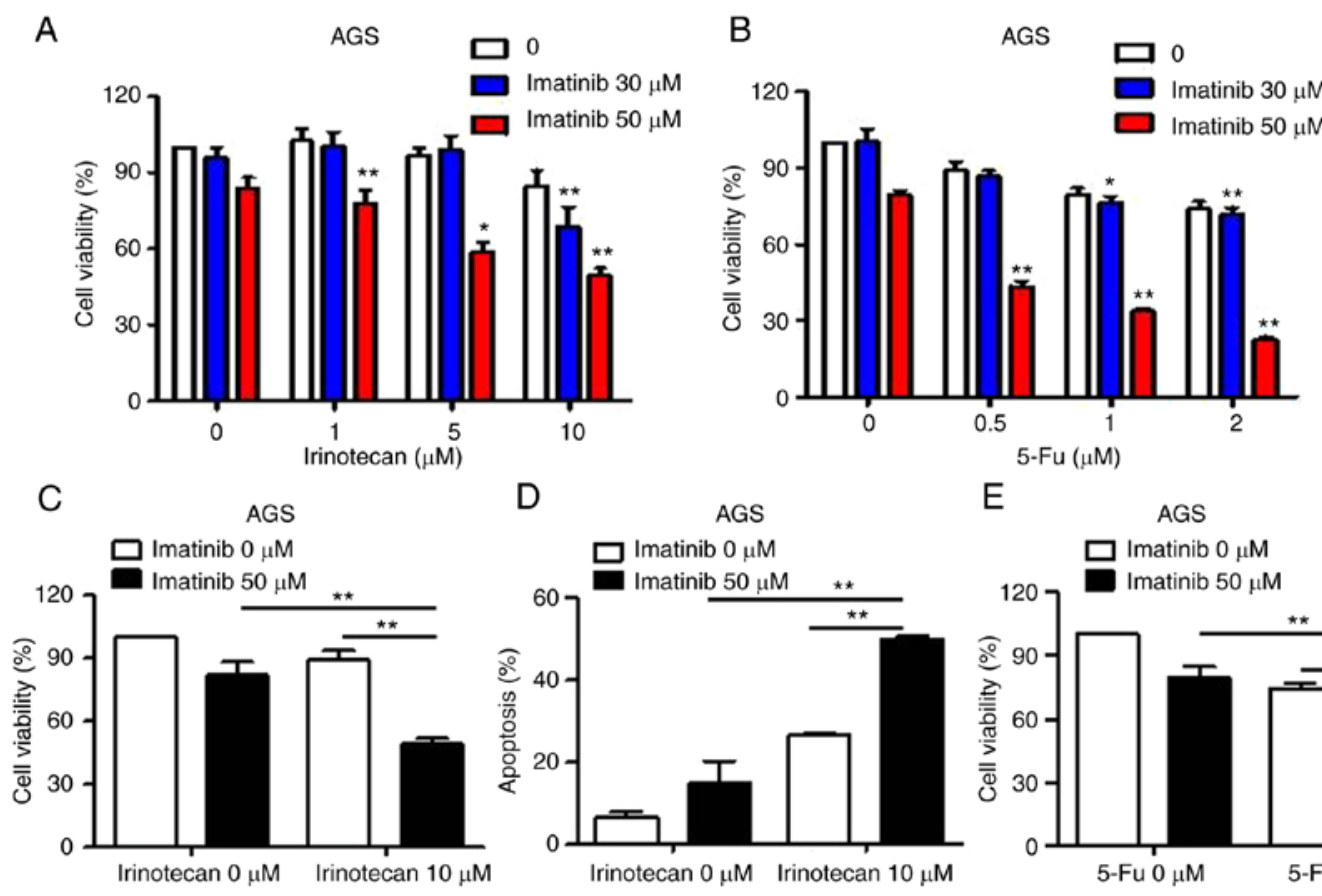

E AGS
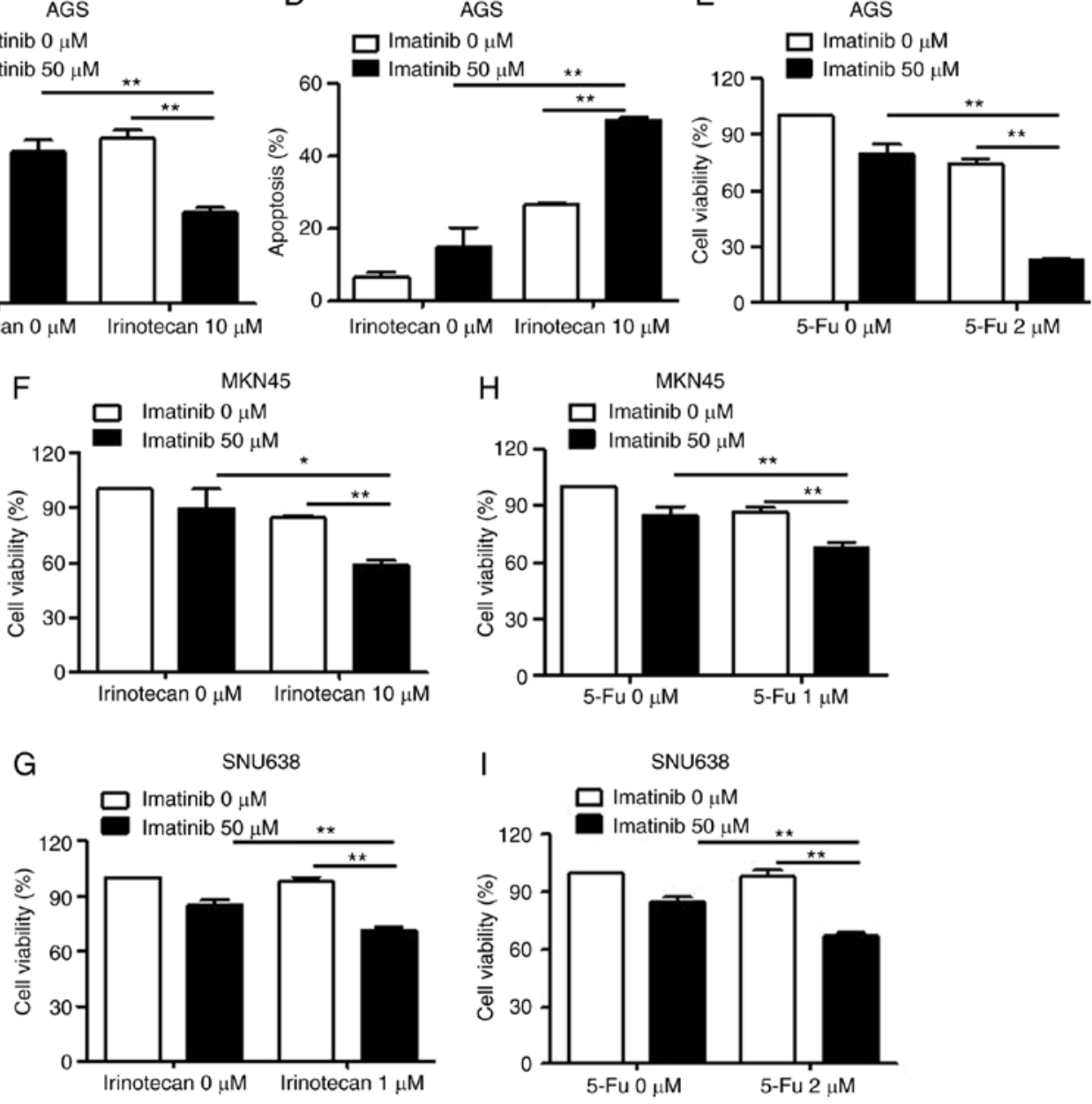

Figure 5. Effects of combination treatment with imatinib and chemotherapy agents on the growth of gastric cancer cells. (A and C) MTT assays were performed to determine the effects of treatment with imatinib or irinotecan alone, or in combination, on the growth of AGS cells. AGS cells were treated with various concentrations of imatinib and irinotecan for $48 \mathrm{~h}$. Data are expressed as the percentage of apoptotic cells compared with that in control cells. " $\mathrm{P}<0.05$ and ${ }^{* *} \mathrm{P}<0.01$, indicate significant difference from values obtained for co-treatment group as compared to the other groups. (D) Cells were stained with Annexin $\mathrm{V}$ and PI, and flow cytometry was performed. Data are expressed as the means \pm SD of three independent experiments. (B and E) AGS cells were treated with various concentrations of imatinib and 5-Fu for $48 \mathrm{~h}$. (F and G) MTT assays were performed to determine the effects of treatment with imatinib or irinotecan alone, or in combination, on the growth of MKN45 and SNU638 cells. Cells were treated with various concentrations of imatinib and irinotecan for $48 \mathrm{~h}$. Each point represents the mean \pm SD of at least three independent experiments. (H and I) MKN45 and SNU638 cells were treated with various concentrations of imatinib and 5-Fu for 48 h. MTT, 3-(4,5-dimethylthiazol-2-ly)-2,5-diphenyl tetrazolium bromide; PI, propidium iodide.

Imatinib-induced apoptosis of gastric cancer cells is mediated by ER stress induction and ROS generation. AGS and SNU638 gastric cancer cells were used to investigate mechanisms underlying imatinib-induced apoptosis. Recent research has indicated that ER stress plays a crucial role in the regulation of apoptosis. To confirm that ER stress was involved in imatinib-induced apoptosis, we examined the expression of ER stress-associated proteins, namely, activating transcription factor 6 (ATF6), glucose-regulated protein 94 (GRP-74), eIF2 $\alpha$, p-eIF2 $\alpha$, IRE1 $\alpha$, p-IRE1 $\alpha$, and CHOP in imatinib-treated AGS and SNU638 cells. Notably, imatinib induced the expression of GRP94, p-eIF2 $\alpha$, p-IRE1 $\alpha$ and CHOP in a concentration- and time-dependent manner in both AGS and SNU638 cells (Fig. 4A-C), indicating that imatinib-induced apoptosis was mediated by the ER stress pathway. A recent study indicated that several anticancer agents induced 


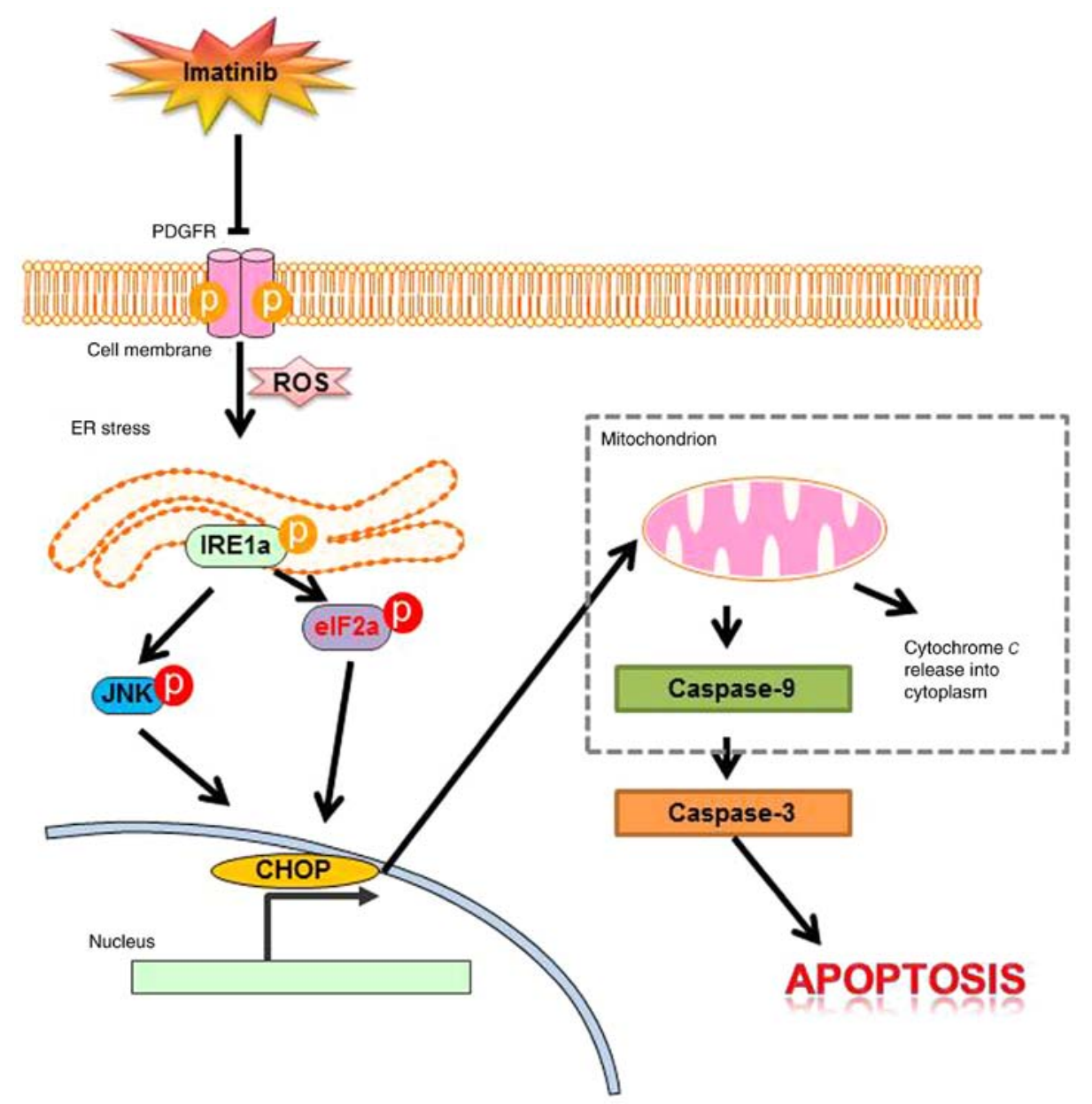

Figure 6. Schematic diagram of the mechanisms underlying imatinib-induced apoptosis via ER stress in gastric cancer cells.

oxidative stress by promoting ROS generation, thus inducing cytotoxicity and apoptosis in cancer cells (19). To investigate the potential role of ROS in imatinib-induced apoptosis, we determined ROS production in imatinib-treated gastric cancer cells using DCFH-DA. Imatinib-treated cells produced significant fluorescence signals. In addition, imatinib induced ROS production in a time-dependent manner (Fig. 4D). $\mathrm{CHOP}^{-/-}$MEFs were resistant to the effects of PARP-1 cleavage compared with wild-type CHOP MEFs (Fig. 4E). Imatinib reduced the elevated ROS levels in $\mathrm{CHOP}^{-/-} \mathrm{MEFs}$, providing evidence that imatinib reduced endogenous ROS levels in a CHOP-dependent manner (Fig. 4F). To examine the relationship between JNK and ER-stress activation during imatinib exposure, AGS cells were pretreated with an inhibitor of JNK (SP600125), then treated with imatinib. Pretreatment with SP600125 significantly decreased imatinib-induced CHOP (Fig. 4G). These results collectively indicated that imatinib-induced apoptosis of gastric cancer cells was mediated by ROS generation and ER stress.

Imatinib and chemotherapy agents synergistically decrease growth of gastric cancer cells. We examined the effect of combination treatment with imatinib and chemotherapy agents on the viability of gastric cancer cells. Treatment with imatinib or irinotecan alone resulted in limited suppression of the viability of gastric cancer cells $(<15 \%)$ at $24 \mathrm{~h}$ (Fig. 5A and C). In contrast, combination treatment with a fixed concentration of irinotecan and varying concentrations of imatinib significantly decreased the viability of gastric cancer cells. We used $50 \mu \mathrm{M}$ imatinib for performing subsequent experiments since this concentration of imatinib significantly reduced cell viability during combination treatment with irinotecan, with only a slight decrease in the percentage of viable cells. Next, we examined whether the combined effect of irinotecan and imatinib treatment on the viability of gastric cancer cells was mediated by apoptotic induction. Co-treatment of gastric cancer cells with irinotecan and imatinib significantly increased the percentage of apoptotic cells, whereas treatment with irinotecan or imatinib alone only slightly increased the percentage of apoptotic cells (Fig. 5D) compared with that among untreated cells. Next, we evaluated the effect of combination treatment with $0.5-2 \mu \mathrm{M} 5-\mathrm{Fu}$ and $30-50 \mu \mathrm{M}$ imatinib on the viability of AGS cells by performing MTT assays. Combination treatment with $50 \mu \mathrm{M}$ imatinib and $2 \mu \mathrm{M} 5-\mathrm{Fu}$ significantly inhibited the growth of AGS cells compared with treatment with imatinib or 5-Fu alone (Fig. 5B and E). Similarly, imatinib also increased irinotecan or 5-Fu-mediated inhibition of MKN45 and SNU638 cell growth (Fig. 5F-I). These findings indicated that combined treatment with imatinib and chemotherapy agents (irinotecan or 5-Fu) effectively induced the apoptosis of gastric cancer cells. 


\section{Discussion}

This is the first study, to the best of our knowledge, to show that imatinib induces the apoptosis of gastric cancer cells through the JNK/ROS/ER stress pathway (Fig. 6). It is important to determine mechanisms underlying imatinib-induced death of gastric cancer cells. Imatinib is a tyrosine kinase inhibitor with activity against the BCR-ABL fusion oncoprotein, PDGFR, and c-KIT in GISTs, prostate cancer, malignant gliomas, and ovarian cancer (26-29). In the present study, c-KIT and BCR-ABL were not expressed in the gastric cancer cell lines (data not shown). Mireskandari et al reported that expression of c-KIT in gastric cancer appears to be a very unlikely event (30). Imatinib was revealed to induce apoptosis in, and may modulate the metastasis of, gastric cancer cells by upregulating KAII expression (31). Biswas et al reported that imatinib induced programmed cell death in retinal ganglion cells by inhibiting PDGFR-mediated PI3K/AKT signaling (32).

Another study suggested that the effect of imatinib on the migration of medulloblastoma cells was not mediated by early induction of apoptosis (33). A recent study indicated that treatment with low and high concentrations of imatinib induced cell growth arrest and apoptosis, respectively, in glioblastoma cells. Consistently, results of the present study revealed that imatinib induced apoptosis at relatively high concentrations (20-100 $\mu \mathrm{M})$, and inhibited cell metastasis at lower concentrations (1-10 $\mu \mathrm{M})$ (data not shown). However, the mechanism underlying imatinib-induced cell death is not completely understood. To clearly determine the mechanism underlying imatinib-induced apoptosis, we identified the possible involvement of a MAPK subfamily protein, since accumulating evidence suggests important regulatory roles of MAPKs in different physiological and pathological processes (34). It was observed that imatinib treatment activated JNK in the late stage, but did not activate ERK. Imatinib-induced activation of JNK/MAPK in the present study indicated that these proteins perform distinct physiological functions in determining the fate of gastric cancer cells. Similarly, Chang et al reported that treatment with high-dose imatinib induced JNK phosphorylation by elevating ROS production in melanoma cells (34). A study by $\mathrm{Yu}$ et al revealed that treatment with $5 \mathrm{mM}$ STI571 interrupted cytoprotective 42/44 MAPK activation response in human myeloid leukemia cells (35). These results indicated that iron chelators activate different target MAPKs in different cell types.

ER stress is suggested to be a significant contributor to cell death. JNK activation plays a significant role in UPR $(36,37)$. Induction of the UPR in the ER, which causes ER stress, induces several pathological and physiological alterations such as glucose depletion, hypoxia, and oxidative stress. Han et al reported that imatinib decreased JNK activation and ER stress in the liver of a diabetic mouse model (38). However, imatinib induced ER stress in gastric cancer cells. Moreover, we found that imatinib induced the apoptosis of gastric cancer cells by modulating ER stress. This is the first study to report that imatinib induced significant apoptosis of gastric cancer cells, which is mediated by ER stress. Imatinib was also revealed to trigger ER stress in CML cells expressing BCR-ABL (39).
In contrast, Zhang et al reported that imatinib did not induce ER stress in Ph1-positive leukemia cells (40). These results indicated that imatinib induced ER stress in a cell-specific manner. IRE1 $\alpha$-mediated JNK activation in the ER induced apoptosis. Notably, we found that imatinib-induced apoptosis of gastric cancer cells was mediated by the JNK/ROS/ER stress pathway.

Generally, for patients with gastric cancer, therapy is combined with cytotoxic chemotherapy and targeted therapy (41). Therefore, it is very important to find a target agent that has synergistic effects while reducing toxicity of cytotoxic agents. Clinical studies on the combination of imatinib, cisplatin and 5-fluoruracil or capecitabine have been reported (42). In one of these clinical trials, the safety and tolerability of combination of imatinib plus 5-fluoruracil was confirmed.

In summary, it was revealed that imatinib is a potent antitumor agent that induces ER stress-mediated apoptosis of gastric cancer cells. We observed that imatinib induced ER stress by activating IRE1 $\alpha$, p-JNK, and CHOP. To the best of our knowledge, this is the first study to determine mechanisms underlying imatinib-induced apoptosis of gastric cancer cells. However, further studies are required to determine the antitumorigenic effects of imatinib in animal models. According to pathological features, it is necessary to further study the anticancer effect of imatinib in gastric cancer cells. Thus, our results indicated that imatinib-induced activation of ER stress is a novel therapeutic strategy for treating gastric cancer.

\section{Acknowledgements}

Not applicable.

\section{Funding}

The present study was supported by a grant from the Korea University Guro Hospital (O1600121) and supported by a grant from the National Research Foundation (NRF) of Korea funded by the Korean government (MSIP) (NRF-2017R1A2B2011684).

\section{Availability of data and materials}

The datasets used during the present study are available from the corresponding author upon reasonable request.

\section{Authors' contributions}

SCO and JLK conceived and designed the study and critically revised the manuscript. JLK and DHL designed and performed the experiments, analyzed the data and were major contributors in writing the manuscript. SJ and BRK supervised the western blot experiments and also performed the statistical analysis. YJN, SHP, MJJ and YAJ performed the Annexin V/PI apoptosis assay experiments. SJ, BRK, YJN, SHP, MJJ and YAJ provided advice on the experiments and technical assistance. SCO supervised the study. All authors read and approved the manuscript and agree to be accountable for all aspects of the research in ensuring that the accuracy or 
integrity of any part of the work are appropriately investigated and resolved.

\section{Ethics approval and consent to participate}

Not applicable.

\section{Patient consent for publication}

Not applicable.

\section{Competing interests}

The authors declare that they have no competing interests.

\section{References}

1. Jemal A, Bray F, Center MM, Ferlay J, Ward E and Forman D: Global cancer statistics. CA Cancer J Clin 61: 69-90, 2011.

2. Nakatani H, Araki K, Jin T, Kobayashi M, Sugimoto T, Akimori T, Namikawa T, Okamoto K, Nakano T, Okabayashi T, et al: STI571 (Glivec) induces cell death in the gastrointestinal stromal tumor cell line, GIST-T1, via endoplasmic reticulum stress response. Int J Mol Med 17: 893-897, 2006.

3. Kadivar A, Kamalidehghan B, Akbari Javar H, Karimi B Sedghi R and Noordin MI: Antiproliferation effect of imatinib mesylate on MCF7, T-47D tumorigenic and MCF 10A nontumorigenic breast cell lines via PDGFR- $\beta$, PDGF-BB, c-Kit and SCF genes. Drug Des Dev Ther 11: 469-481, 2017.

4. Donovan J, Abraham D and Norman J: Platelet-derived growth factor signaling in mesenchymal cells. Front Biosci 18: 106-119, 2013.

5. Cumpănas AA, Cimpean AM, Ferician O, Ceausu RA, Sarb S, Barbos V, Dema A and Raica M: The involvement of PDGF-B/PDGFR $\beta$ axis in the resistance to antiangiogenic and antivascular therapy in renal cancer. Anticancer Res 36: 2291-2295, 2016.

6. Kazlauskas A: PDGFs and their receptors. Gene 614: 1-7, 2017.

7. Pietras K, Sjöblom T, Rubin K, Heldin CH and Ostman A: PDGF receptors as cancer drug targets. Cancer Cell 3: 439-443, 2003.

8. Minamino T, Komuro I and Kitakaze M: Endoplasmic reticulum stress as a therapeutic target in cardiovascular disease. Circ Res 107: 1071-1082, 2010.

9. Tsai YC and Weissman AM: The unfolded protein response, degradation from endoplasmic reticulum and cancer. Genes Cancer 1: 764-778, 2010.

10. Malhotra JD, Miao H, Zhang K, Wolfson A, Pennathur S, Pipe SW and Kaufman RJ: Antioxidants reduce endoplasmic reticulum stress and improve protein secretion. Proc Natl Acad Sci USA 105: 18525-18530, 2008.

11. Thuerauf DJ, Marcinko M, Gude N, Rubio M, Sussman MA and Glembotski CC: Activation of the unfolded protein response in infarcted mouse heart and hypoxic cultured cardiac myocytes. Circ Res 99: 275-282, 2006.

12. Xu C, Bailly-Maitre B and Reed JC: Endoplasmic reticulum stress: Cell life and death decisions. J Clin Invest 115: 2656-2664, 2005.

13. Mansfield KD, Simon MC and Keith B: Hypoxic reduction in cellular glutathione levels requires mitochondrial reactive oxygen species. J Appl Physiol 97: 1358-1366, 2004.

14. Waypa GB, Guzy R, Mungai PT, Mack MM, Marks JD, Roe MW and Schumacker PT: Increases in mitochondrial reactive oxygen species trigger hypoxia-induced calcium responses in pulmonary artery smooth muscle cells. Circ Res 99: 970-978, 2006.

15. Ostadal P, Elmoselhi AB, Zdobnicka I, Lukas A, Elimban V and Dhalla NS: Role of oxidative stress in ischemia-reperfusion-induced changes in $\mathrm{Na}^{+}, \mathrm{K}^{+}$-ATPase isoform expression in rat heart. Antioxid Redox Signal 6: 914-923, 2004

16. Nojiri H, Shimizu T, Funakoshi M, Yamaguchi O, Zhou H, Kawakami S, Ohta Y, Sami M, Tachibana T, Ishikawa H, et al: Oxidative stress causes heart failure with impaired mitochondrial respiration. J Biol Chem 281: 33789-33801, 2006.

17. Morgan WA: DNA single-strand breakage in mammalian cells induced by redox cycling quinones in the absence of oxidative stress. J Biochem Toxicol 10: 227-232, 1995.
18. Devasagayam TP, Tilak JC, Boloor KK, Sane KS, Ghaskadbi SS and Lele RD: Free radicals and antioxidants in human health: Current status and future prospects. J Assoc Physicians India 52: 794-804, 2004.

19. Gong K, Xie J, Yi H and Li W: CS055 (Chidamide/HBI-8000), a novel histone deacetylase inhibitor, induces $\mathrm{G}_{1}$ arrest, ROS-dependent apoptosis and differentiation in human leukaemia cells. Biochem J 443: 735-746, 2012.

20. Chang YJ, Huang YP, Li ZL and Chen CH: GRP78 knockdown enhances apoptosis via the down-regulation of oxidative stress and Akt pathway after epirubicin treatment in colon cancer DLD-1 cells. PLoS One 7: e35123, 2012.

21. Atari-Hajipirloo S, Nikanfar S, Heydari A and Kheradmand F: Imatinib and its combination with 2,5-dimethyl-celecoxibinduces apoptosis of human HT-29 colorectal cancer cells. Res Pharm Sci 12: 67-73, 2017.

22. Akram AM, Iqbal Z, Akhtar T, Khalid AM, Sabar MF, Qazi MH, Aziz Z, Sajid N, Aleem A, Rasool M, et al: Presence of novel compound BCR-ABL mutations in late chronic and advanced phase imatinib sensitive CML patients indicates their possible role in CML progression. Cancer Biol Ther 18: 214-221, 2017.

23. Mahon FX: Discontinuation of TKI therapy and 'functional' cure for CML. Best Prac Res Clin Haematol 29: 308-313, 2016.

24. Abu-Amna M, Awadie H and Bar-Sela G: Imatinib-induced gastrointestinal vascular ectasia in a patient with advanced gIST: Case report and literature review. Anticancer Res 36: 6151-6154, 2016.

25. Sui X, Kong N, Ye L, Han W, Zhou J, Zhang Q, He C and Pan H: p38 and JNK MAPK pathways control the balance of apoptosis and autophagy in response to chemotherapeutic agents. Cancer Lett 344: 174-179, 2014.

26. Balachandran VP, Cavnar MJ, Zeng S, Bamboat ZM, Ocuin LM, Obaid H, Sorenson EC, Popow R, Ariyan C, Rossi F, et al: Imatinib potentiates antitumor $\mathrm{T}$ cell responses in gastrointestinal stromal tumor through the inhibition of Ido. Nat Med 17: 1094-1100, 2011.

27. Nakatani H, Kobayashi M, Jin T, Taguchi T, Sugimoto T, Nakano T, Hamada S and Araki K: STI571 (Glivec) inhibits the interaction between c-KIT and heat shock protein 90 of the gastrointestinal stromal tumor cell line, GIST-T1. Cancer Sci 96: 116-119, 2005.

28. Matei D, Emerson RE, Lai YC, Baldridge LA, Rao J, Yiannoutsos C and Donner DD: Autocrine activation of PDGFRalpha promotes the progression of ovarian cancer. Oncogene 25: 2060-2069, 2006.

29. Li J, Kleeff J, Guo J, Fischer L, Giese N, Büchler MW and Friess H: Effects of STI571 (gleevec) on pancreatic cancer cell growth. Mol Cancer 2: 32, 2003.

30. Mireskandari M, Shafaii AF, Kayser G and Kayser K: Lack of CD117 and rare bcl-2 expression in stomach cancer by immunohistochemistry. An immunohistochemical study with review of the literature. Diagn Pathol 1: 7, 2006.

31. Shandiz SA, Farasati S, Saeedi B, Baghbani-Arani F, Asl EA, Keshavarz-Pakseresht B, Rahimi A, Assadi A, Noorbazargan H, RahimpourHesari M, et al: Up regulation of KAI1 gene expression and apoptosis effect of imatinib mesylate in gastric adenocarcinoma (AGS) cell line. Asian Pac J Trop Dis 6: 120-125, 2016.

32. Biswas SK, Zhao Y and Sandirasegarane L: Imatinib induces apoptosis by inhibiting PDGF-but not insulin-induced PI 3-kinase/Akt survival signaling in RGC-5 retinal ganglion cells. Mol Vis 15: 1599-1610, 2009.

33. Abouantoun TJ and MacDonald TJ: Imatinib blocks migration and invasion of medulloblastoma cells by concurrently inhibiting activation of platelet-derived growth factor receptor and transactivation of epidermal growth factor receptor. Mol Cancer Ther 8: 1137-1147, 2009.

34. Chang SP, Shen SC, Lee WR, Yang LL and Chen YC: Imatinib mesylate induction of ROS-dependent apoptosis in melanoma B16F0 cells. J Dermatol Sci 62: 183-191, 2011.

35. Yu C, Krystal G, Varticovksi L, McKinstry R, Rahmani M, Dent P and Grant S: Pharmacologic mitogen-activated protein/extracellular signal-regulated kinase kinase/mitogen-activated protein kinase inhibitors interact synergistically with STI571 to induce apoptosis in Bcr/Abl-expressing human leukemia cells. Cancer Res 62: 188-199, 2002.

36. Lenna S, Han R and Trojanowska M: Endoplasmic reticulum stress and endothelial dysfunction. IUBMB Life 66: 530-537, 2014

37. Kim JL, Lee DH, Na YJ, Kim BR, Jeong YA, Lee SI, Kang S, Joung SY, Lee SY, Oh SC and Min BW: Iron chelator-induced apoptosis via the ER stress pathway in gastric cancer cells. Tumour Biol 37: 9709-9719, 2016. 
38. Han MS, Chung KW, Cheon HG, Rhee SD, Yoon CH, Lee MK, Kim KW and Lee MS: Imatinib mesylate reduces endoplasmic reticulum stress and induces remission of diabetes in $d b / d b$ mice. Diabetes 58: 329-336, 2009.

39. Pattacini L, Mancini M, Mazzacurati L, Brusa G, Benvenuti M, Martinelli G, Baccarani M and Santucci MA: Endoplasmic reticulum stress initiates apoptotic death induced by STI571 inhibition of p210 bcr-abl tyrosine kinase. Leuk Res 28: 191-202, 2004.

40. Zhang X, Inukai T, Akahane K, Hirose K, Kuroda I, Honna H, Goi K, Kagami K, Tauchi T, Yagita H, et al: Endoplasmic reticulum stress inducers, but not imatinib, sensitize Philadelphia chromosome-positive leukemia cells to TRAIL-mediated apoptosis. Leuk Res 35: 940-949, 2011.
41. Lopez A, Harada K, Mizrak Kaya D and Ajani JA: Current therapeutic landscape for advanced gastroesophageal cancers. Ann Transl Med 6: 78-96, 2018.

42. Mayr M, Becker K, Schulte N, Belle S, Hofheinz R, Krause A, Schmid RM, Röcken C and Ebert MP: phase I study of imatinib, cisplatin and 5-fluoruracil or capecitabine in advanced esophageal and gastric adenocarcinoma. BMC Cancer 12: 587-593, 2012. Attribution-NonCommercial-NoDerivatives 4.0 International (CC BY-NC-ND 4.0) License. 